\title{
HOJE AMANUENSE. AMANHÃ DIPLOMATA? - A MEMÓRIA EM O AMANUENSE BELMIRO E MEMORIAL DE AIRES
}

Patrícia da Silva Cardoso*

\section{Realidade, Ficção Memória}

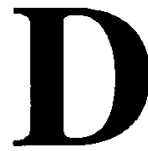

esde seu lançamento, em 1937, $O$ amanuense Belmiro, de Cyro dos Anjos, vem sendo considerado pela crítica um romance "machadiano". João Gaspar Simões, num texto de 1939, o primeiro estudo mais longo sobre o romance, aproxima Cyro dos Anjos e Machado de Assis, por ver que a obra de ambos tem um "tom caricatural" . Dez anos depois, num artigo sobre escritores mineiros, Carlos Drummond de Andrade filia $O$ amanuense a "uma tradição artística brasileira encabeçada por Machado de Assis"2 . Outros críticos, se não apontaram diretamente a ligação entre os dois escritores, caracterizam de tal forma o texto de Cyro dos Anjos que é impossível deixar de remeter-nos a Machado:

* Doutoranda em Teoria Literária pela UNICAMP.

I SIMŌES, João Gaspar Simōes. O Amanuense Belmiro. In: Crítica l: a prosa e o romance contemporaneos. Porto, Livraria Latina Editora, 1942, p. 344.

2 ANDRADE, Carlos Drummond de.O Amanuense, o Trovador e o Cigano. Follha da Manhã, 31 jul. 1949, São Paulo. 
Seu humor, nos momentos de síntese, isto é, de poesia verdadeira, exprime-se numa fórmula de lirismo e ironia, cinismo e sentimentalismo, e tudo dosado com sutileza, com uma graça extrema. ${ }^{3}$

Traços como humor, ironia, cinismo ou sutileza, que Eduardo Frieiro localiza em $O$ amanuense, são freqüentemente atribuídos a Machado de Assis, e se tornaram mesmo lugar comum na crítica a respeito de sua obra. Essa aproximação promovida constantemente pela crítica acabou por sufocar um pouco o que poderíamos chamar de identidade da obra de Cyro dos Anjos, transformando-o em mais um machadiano, o que nos permitiria concluir que um romance como $O$ amanuense Belmiro tivesse seu valor determinado em função de ser construído a partir das eficazes "fórmulas" de Machado. Aliás, a respeito das implicações dessa tendência para se estabelecer Machado como um paradigma - ou matriz - das letras brasileiras, há dois registros curiosos. $\mathrm{O}$ primeiro deles deve-se a José Lins do Rego, que assim encerra uma entrevista com Vianna Moog:

E vai ele falando, com entusiasmo, do romance e da poesia brasileira de nossos dias. Descobre em mim influência de Eça de Queirós. Mas tudo isto sem agressividade, a tal agressividade com que os machadianos se voltam contra Graciliano Ramos e Cyro dos Anjos, querendo encontrar em todo mundo pedaços da riqueza do velho Machado. ${ }^{4}$

As palavras de Lins do Rego remetem à feição pouco lisonjeira que o atributo "machadiano" poderia adquirir, justamente porque classificar assim um autor equivaleria muitas vezes a dizer que o mesmo estaria tirando proveito do mestre, meramente copiando seu estilo.

O segundo registro é de Mário de Andrade, ao falar sobre a peculiaridade diferenciadora dos escritores mineiros. Ao incluir o humor como um dos elementos constantes da base dessa peculiaridade, ele diz:

3 FRIEIRO, Eduardo. O Amanuense Belmiro, Romance de Cyro dos Anjos. In:

Páginas de crítica e outros escritos. Belo Horizonte: Itatiaia, 1955, p. 41.

4 REGO, José Lins do. Vianna Moog. In: Gordos e Magros, Rio de Janeiro: Casa do Estudante do Brasil, 1942, p. 161. 
Já em arte, $r$ mineiro desconfia de qualquer servilismo intelectual. (...) Destas coisas os mineiros desconfiam para a liberdade mansa do seu pensamento. Às vezes reagem mesmo, pelo humorismo; e não venham me falar de Machado de Assis, por favor! (...) Porque há um humorismo mineiro, coisa profunda, tradicional, que é uma atitude proveniente de uma natureza, e seria ridículo explicar como efeito de imitação. ${ }^{5}$

O que faz Mário de Andrade é reclamar a independência do humor, sua existência fora dos limites do universo machadiano. Foi assim que, sendo identificado como herdeiro de tão ilustre nome, Cyro dos Anjos viu serem reduzidas a essa simples identificação as referências à sua obra. De qualquer modo, comparar duas obras só faz sentido se estabelecermos um diálogo entre elas que redimensione um universo comum a seus autores. No caso de $O$ amanuense Belmiro e Memorial de Aires, os dois romances aqui discutidos, o elemento que promove essa ligação é a memória, tal como é explorada por um e outro autor.

O processo criador dos dois romancistas - que promove a fusão de elementos ficcionais e "verídicos" - e sua fixação em temas vinculados à memória parecem-me pontos mais consistentes e mais instigantes para se pensar em um possível diálogo entre eles.

No "Prefácio Inútil" às memórias de Oswald de Andrade, Antonio Candido refere-se a como a ficção - ou a obra - pode se fundir às memórias de certos escritores. Essa classe de autores, à qual Oswald pertenceria, tende a revestir suas lembranças de um caráter ficcional,

fragmentando a realidade na poalha dos dados da sensibilidade e desta maneira dando acesso a um mundo tornado equivalente ao imaginário da ficção. Aqui, nada separa Oswald de Andrade de seus personagens. Ele se torna seu maior personagem, operando a fusão poética do real e do fantástico. ${ }^{6}$

5 ANDRADE, Mário de. Letras Mineiras. In: Vida literária, São Paulo: Edusp/Hucitec, 1993, p. 127.

6 CANDIDO, Antonio. Prefácio Inútil. In: ANDRADE, Oswald de. Um homem sem profissão: sob as ordens de mamäe. Rio de Janeiro: José Olympio, 1954, p. 13. 
Essa proximidade entre realidade e ficção também parece surgir na obra de Cyro dos Anjos e de Machado de Assis, mas de uma maneira inversa: ao invés de a ficção invadir os domínios da realidade do autor, a realidade é que penetra em suas obras de ficção.

A origem do personagem-narrador de $O$ amanuense, Belmiro Borba, traz essa carga de, na falta de outro termo, "realidade" do autor. Anos antes de escrever o romance, Cyro dos Anjos publicava crônicas em jornais de Belo Horizonte que assinava com o pseudônimo de Belmiro Borba. O comentário do próprio Cyro a esse respeito, em entrevista, ilustra bem essa proximidade entre personagem (ficção) e autor (realidade):

sucede que esses dois palmos de coluna diários começaram a se encadear, tanto na matéria como no tom, na atitude. Assim, o pseudônimo virou personagem, e personagem autor, no qual se projetava, em parte, o autor verdadeiro. O pseudônimo converteu-se, assim, em heterônimo. ${ }^{7}$

Dessa forma, um pseudônimo, nome falso que aponta para a mesma pessoa que o nome real, acaba se tornando um heterônimo, outro nome que aponta, como no caso de Fernando Pessoa, que consagrou o termo, para uma relação mais complexa, em que o real se funde com o criado, em que o ficcional empresta dados da realidade para existir como algo independente, numa dialética do mesmo e do outro.

No que diz respeito a Machado de Assis, pode-se localizar também um personagem que se funde ao autor. Em sua biografia do escritor, Lúcia Miguel Pereira indica esse processo desde seus primeiros escritos, que também teve como embrião um pseudônimo, Job, com que assinava suas primeiras crônicas: "esse Job foi a encarnação de um tipo que veio acompanhando Machado a vida toda, se foi confundindo com ele e acabou por dominá-lo: o do conselheiro Aires, diplomata aposentado, homem polido e medido, que se punha à margem da existência e apreciava, entre interessado e entediado, o espetáculo da vida humana"8. Assim, Aires surge também como um heterônimo que se forma após uma longa gestação - de mais de cinqüenta anos.

7 Ver a entrevista intitulada "Amores e Dores de um Estrategista da Literatura", $O$ Globo, 29 nov. 1981, Rio de Janeiro. 272.

8 PEREIRA, Lúcia Miguel. Machado de Assis. São Paulo: Editora Nacional, 1946, p. 
Essa ligação heteronímica entre Machado e seus personagens também é apontada por alguns críticos em textos mais recentes. Quando Alfredo Bosi se pergunta

o compasso de Aires será o da figura ideológica do último Machado? O disfarce estratégico (e, afinal, definitivo) de uma aturada consciência social e política? ${ }^{9}$,

indica, pelo menos, a possibilidade de identificação entre Machado e Aires. Mesmo num estudo de caráter diferente, como é Ao vencedor as batatas, aparece essa ligação entre Machado e uma de suas personagens, a Guiomar de A mão e a luva ${ }^{10}$.

Não é coincidência, então, que tanto Cyro dos Anjos quanto Machado de Assis explorem consideravelmente a questão da memória em seus romances. A obra de Cyro do Anjos é quase toda composta sob a forma de diários e memórias. Seu segundo romance, Abdias, como $O$ amanuense, é narrado em primeira pessoa e se constitui mesmo no diário do professor Abdias. Apenas seu terceiro romance, Montanha, quebra essa conduta: sua temática política é narrada em teceira pessoa, ainda que vários trechos do diário de uma personagem apareçam reproduzidos ao longo da narrativa. O restante da obra, além de ensaios, conta justamente com dois livros de memórias, que atualmente são editados juntos, num volume intitulado $A$ menina do sobrado.

Quanto a Machado, nos romances de sua fase "realista", contrariamente ao que era considerado desejável em sua época, o uso do foco narrativo em terceira pessoa, optou pela primeira pessoa em três entre cinco obras: Memórias póstumas de Brás Cubas, Dom Casmurro, e Memorial de Aires. Nelas, a memória, tanto quanto na obra de Cyro dos Anjos, ocupa posição central. E não apenas no Memorial de Aires, mas também em Dom Casmurro, onde aparece a idéia de resgate pela memória do "tempo perdido", implícita no desejo do personagem-narrador Bentinho de juntar infância e velhice. Além disso, não se pode esquecer que em Esaú e Jacó, um romance cujo narrador está mais próximo da onisciência, a figura do Conselheiro Aires já é introduzida, justamente na

9 BOSI, Alfredo. Uma Figura Machadiana, In: . Céu, inferno. São Paulo: Ática, 1988 , p. 66.

10 Na verdade, Roberto Schwarz faz essa aproximação a partir da ascensão social de Machado e Guiomar. Ver o capítulo "A Māo e a Luva", em Ao vencedor as batatas. São Paulo: Duas Cidades, 1981, p. 73-86. 
posição de personagem-narrador, registrando fatos que ele havia presenciado num volume guardado junto com seu memorial.

Retomando as considerações feitas a partir da observação de Candido sobre o possível encontro entre memória e fiç̧ão, pode-se notar que, em obras que promovem esse encontro, como é o caso de $O$ amanuense e Memorial de Aires, cria-se um trinômio: realidade-ficção-memória. E é esse trinômio, campo comum entre Cyro e Machado, que abordo aqui, especialmente através dos personagens-narradores Belmiro e Aires.

Por outro lado, para se redimensionar esse universo comum, é preciso estar atento, como adverte Candido, menos para as semelhanças entre os dois romancistas e mais para uma diferença fundamental entre eles: além da visão dramática da vida, característica da obra de Machado, Cyro possui um "sentido poético das coisas e dos homens" 11 . É essa alternância entre, por assim dizer, o dramático e o lírico que, levada em conta ao observarmos como a memória funciona para os dois personagens-narradores, permite que a abordagem vá além da simples exposição de elementos comuns entre os dois textos.

\section{Memória e identidade}

Uma característica significativa do Conselheiro Aires é a tendência para a neutralidade, muito útil para um diplomata, como ele mesmo lembra mais de uma vez. Nada parece assustá-lo ou surpreendê-lo:

Se eu não tivesse os olhos adoentados dava-me a compor outro Eclesiastes, à moderna, posto nada deva haver de moderno depois daquele livro. Já dizia ele que nada era novo debaixo do sol, e se o não era então, não o foi nem será nunca mais. Tudo é assim contraditório e vago também. ${ }^{12}$

E tal é a distância que o Conselheiro mantém do mundo que até mesmo o movimento da vida - suas contradições - é considerado por ele como parte das expectativas. s/d, p. 87.

1) CANDIDO, Antonio. Estratégia. In: Brigada Ligeira. São Paulo: Martins,

12 MACHADO DE ASSIS. Memorial de Aires. São Paulo: Cultrix, 1961, p. 86. 
Já Belmiro Borba vive em estado de permanente contradição, sofrendo as consequiências disso. A "visão dramática" da vida, que Aires possui, se entendermos dramática em sentido próprio, associado ao teatral, implica um distanciamento, uma posição de espectador diante da vida.

Ao alternar essa "visão dramática" com a lírica, de percepção do estado "poético das coisas e dos homens", Belmiro se vê envolvido numa situação ambígua, quase contraditória, na medida em que o lírico remete para uma aproximação, um envolvimento pessoal profundo no espetáculo. O resultado disso é que suas atitudes são também contraditórias, o que já notou Roberto Schwarz:

(...) em Belmiro convivem os inconciliáveis: o democratismo e o privilégio, o racionalismo e o apego à tradição, o impulso confessional, que exige veracidade e o temor à luz clara. ${ }^{1 .}$

O amanuense, ao contrário do diplomata, enuncia uma espécie de renúncia à vida, um acomodamento à solidão, que ele persegue mas não alcança. Assim é que ele chega a admitir o seguinte:

Há muito que ando em estado de entrega.Entregar-se a gente às puras e melhores emoções, renunciar aos rumos da inteligência e viver simplesmente pela sensibilidade - descendo de novo, cautelosamente, à margem do caminho, o véu que cobre a face do real das coisas e que foi, aqui e ali, descerrado por mão imprudente - parece-me a única estrada possível. Onde houver claridade converta-se em fraca luz de crepúsculo, para que as coisas se tornem indefinidas e possamos gerar nossos fantasmas. Seria uma fórmula para nos conciliarmos com o mundo. ${ }^{14}$

Essa contradição que envolve Belmiro transparece na própria construção da narrativa. Enquanto as anotações de Aires - tanto o registro dos fatos quanto as considerações sobre eles - mantêm um certo distanciamento da matéria narrada, através do emprego constante da ironia e da auto-ironia, Belmiro conta

13 SCHWARZ, Roberto. Sobre "O Amanuense Belmiro". In: Opai de familia e outros estudes. Rio de Janeiro: Paz e Terra, 1979, p. 19.

14 ANJOS, Cyro dos. O amanuense Belmiro. Rio de Janeiro, José Olympio, 1980, p. 21. 
as cenas que viveu até com entusiasmo, reservando a ironia e o distanciamento quase sempre para um comentário final. Ou seja, os julgamentos de Aires parecem anteceder sua narrativa, formando mesmo um filtro a partir do qual os fatos são registrados, já pensados e analisados. Enquanto isso, Belmiro Borba coloca-se como agente nos acontecimentos e somente depois de narrá-los busca uma atitude distanciada, que proporciona o julgamento, geralmente exposto através de "tiradas", frases rápidas carregadas de ironia.

A mudança de tom a que Belmiro submete sua narrativa revela a busca de uma posição de distanciamento, por representar uma intervenção racional, espécie de "quebra" proposital no clima de envolvimento com os fatos, no próprio fluxo de suas lembranças.

O comportamento do Conselheiro Aires aparece, assim, como uma espécie de "estado ideal" para Belmiro. Na verdade, apesar de já maduro, com 38 anos, ele passa por um processo de dúvidas e hesitações característico de quem procura uma identidade.

Ao discutir as relações entre identidade cultural e arqueologia, Ulpiano Bezerra de Meneses coloca a memória como "suporte essencial" para a construção de uma identidade. A memória teria a função de preservar valores, sendo por isso um elemento primordial na construção da identidade. Mas, dialeticamente, essa força conservadora da memória seria também responsável pela viabilização de mudanças:

Se não houver memória, a mudança será sempre fator de alienação e desagregação, pois inexistiria uma plataforma de referência, e cada ato seria uma reação mecânica, uma resposta nova e solitária a cada momento, um mergulho do passado esvaziado para o vazio do futuro ${ }^{15}$.

Visto desse modo o papel da memória, pode ser este o sentido que tem o fato de Belmiro Borba resolver, antes mesmo de atingir a velhice, escrever seu memorial: definir para si uma identidade, que permita a ele enxergar-se como parte de um universo, ao mesmo tempo que o instigue a seguir vivendo:

15 MENESES, Ulpiano Bezerra de. Identidade Cultural e Arqueologia. $l n$ : BOSI, Alfredo. (org.) Cultura brasileira. São Paulo: Ática, 1988, p. 182. 
Não sei bem o que me sairá das entranhas. Comecei contando o Natal que acabou e falando nos amigos e na parentela. Meu desejo não é, porém, cuidar do presente: gostaria apenas de reviver o pequeno mundo caraibano, que hoje avulta a meus olhos. Minha vida parou, e desde muito me volto para o passado, perseguindo imagens fugitivas de um tempo que se foi. Procurando-o procurarei a mim próprio. ${ }^{16}$

De fato, esse é todo o movimento do livro, em direção ao passado e, então, de projeção para o futuro. Ao deparar-se com o passado, no entanto, Belmiro acaba esvaziando o presente na tentativa de tornar possível ao menos um futuro "pacificado", como ele mesmo diz, a partir das referências fornecidas pelo passado.

A maneira como, a certa altura, o amanuense trata de sua vida amorosa ilustra perfeitamente esse duplo movimento no tempo. Durante um baile de Carnaval, "levado pela multidão", ele se vê ao lado de uma moça, Carmélia. Ao peceber a mão branca da moça pousada em seu braço, Belmiro lembra-se de um conto de fadas cuja personagem principal é Arabela, donzela que morreu de amor. Através desse velho mito infantil, ele projeta em Carmélia a figura de um antigo amor, Camila. A figura de Carmélia, presente, esvazia-se diante da imagem do amor adolescente, Camila: desta forma, o passado, a memória, é que passa a existir, e sua relação com Carmélia, na verdade, torna-se uma relação com a imagem de Camila.

A resolução para a dolorosa superposição de elementos do passado no presente, Belmiro reserva para o futuro, um futuro de neutralidade, de apaziguamento: "aos sessenta anos, um Belmiro triste, céptico, mas pacificado, já não sofrerá donzelas nem arabelas"17. Mais do que simplesmente para o futuro, essa observação do narrador aponta para a velhice - onde se encontra o Conselheiro Aires.

Aqui, uma breve análise da memória, tal como se manifestaria entre os velhos, pode colaborar para tornar mais clara a projeção feita por Belmiro. Além disso, depois da apresentação de uma diferença entre os personagens de Cyro dos Anjos e Machado de Assis, passo a um novo ponto que, se não remete a uma semelhança absoluta, promove um interessante diálogo entre as duas obras: a questão do envelhecimento.

16 ANJOS, Cyro dos. O amanuense Belmiro. Rio de Janeiro: José Olympio, 1980, p. 15.

17 lbid., p. 30. 


\section{Memória e Velhice}

A partir do trabalho de Henri Bergson, Ecléa Bosi, em seu Memória e sociedade - Lembranças de velhos, argumenta que a memória funcionaria em dois níveis: o primeiro, chamado de memória-hábito, seria responsável pelos mecanismos motores encarregados da execução das ações cotidianas, ou seja, o "lugar" da memória onde o como fazer as coisas do dia-a-dia fica gravado. De outro lado, haveria a lembrança que aparece independentemente de quaisquer hábitos: "lembranças isoladas, singulares, que constituiriam autênticas ressurreições do passado" 18 .

Nos velhos, ocorreria uma espécie de interpenetração desses dois níveis, na medida em que a própria lembrança se converteria em hábito, deixando de necessitar de um momento certo para ocorrer; ou seja, para o velho, afastado das atividades práticas do dia-a-dia, a lembrança se torna ação única e, portanto, cotidiana: "o velho típico já não aprenderia mais nada, pois sua vida psicológica já estaria presa a hábitos adquiridos, inveterados; e, em compensação, nos longos momentos de inação poderia perder-se nas imagens-lembrança"19"

Transformada em comportamento cotidiano, a memória seria, para o velho, um fim em si. As lembranças não recuperariam nem projetariam nada, convertendo-se o passado em presente, enquanto o futuro se esvaziaria, constituindo-se apenas em uma espera da morte.

Nesse aspecto, o Conselheiro Aires é um velho típico, quando afirma: "Certamente me lembram cousas e pessoas de longe, diversões, paisagens, costumes, mas não morro de saudade por nada. Aqui estou, aqui vivo, aqui morrerei" ${ }^{20}$. Ele lembra fatos que não interferem mais em sua vida, as pessoas e coisas do passado convivem com ele sem influenciar seu comportamento não causam nem mesmo saudade. Também não há futuro, na medida em que o aqui aparece associado à permanência e à morte, nunca à mudança.

O Conselheiro, então, para usar o termo de Belmiro, está pacificado, pois já envelheceu. Sua autoproclamada neutralidade não é apenas um dado natural de sua personalidade, como ele insiste em afirmar, fruto da experiência de diplomata, mas também uma característica da idade.

18 BOSI., Memória e sociedade: Lembranças de velhos. São Paulo: T. A. Quei'roz/Edusp, 1987, p. 11.

19 Ibid, p. 12.

20 MACHADO DE ASSIS. Memorial de Aires. São Paulo: Cultrix, 1971, p. 23. 
Ecléa Bosi chega mesmo a se referir ao Memorial em seu trabalho sobre a velhice, como forma de ilustrar a relação entre velhos e jovens, que acaba sempre com a marginalização do velho:

(...) o comum dos aprendizes, quando a fonte doadora esgotou seus benefícios, volta-lhe as costas e busca outras fontes. Isto é humano, dirão, é a lei da superação da geração mais velha pela mais jovem. ${ }^{21}$

Ecléa reforça o fato de Machado ter escrito sobre o que ela chama de ingratidão em relação aos velhos justamente em sua velhice.

Isso leva a considerar a influência de mais um aspecto, o social, no decantado distanciamento dos fatos de Aires. Devido ao espaço - ou justamente à sua falta - que o velho ocupa na sociedade. A solidão de Aires não existe por ser simplesmente cultivada, ela é imposta, tornando-se inevitável.

Também a posição do personagem de Cyro dos Anjos pode ser enriquecida com as considerações de Ecléa Bosi. O procedimento de Belmiro, de sempre intervir racionalmente no sentido de afastar-se de observações que indiquem seu envolvimento com os fatos - e mesmo com as pessoas - ganha feições de uma preparação para a velhice. Esse trajeto em direção à velhice e à solidão é entrevisto pelo próprio personagem, que tem poucos amigos e procura mantê-los, chegando a sacrificar seus pontos de vista na tentativa de evitar discussões:

Os companheiros são raros, precisamos conservá-los a todo custo. E quando não possamos ser amigos cem por cento, sejamos cinquienta ou vinte. Quando encontro, em alguém, cinco por cento de afinidade, contento-me com essa escassa percentagem. $^{22}$

Se esse tipo de comportamento revela uma vontade de evitar que a solidão - e a velhice - chegue, não implica na crença que isso não vá acontecer. A própria tentativa consciente de preservação de algo só pode existir se se crê que sua

21 BOSI, Ecléa, op. cit., p. 34.

22 ANJOS, Cyro dos, op. cit., p. 86-87. 
extinção possa acontecer - ninguém tenta preservar o que não tem chance de perder.

Belmiro se encontra num meio-termo entre a juventude e a velhice, num momento de transição e, como tal, um momento ambíguo, de insegurança. Talvez por isso a ambigüidade de suas atitudes seja tão marcada e as dúvidas surjam para ele com tanta naturalidade. É nesse sentido que Aires está num "estado ideal" em relação a Belmiro, pois já completou o percurso rumo à solidão e a velhice. A forma como os dois se lembram de uma mesma situação da infância - as festas de São João - esclarece bem as diferentes posições de ambos.

Quando se refere àquelas festas, o Conselheiro Aires lembra que se tirava a sorte $\mathrm{e}$

(...) passavam-se as horas até chegar o sono. Agora, meu sono amigo, só tu virás daqui a uma ou duas horas, sem livros de sorte nem dados. Quando muito trarás sonhos e já não serão os mesmos de outro tempo. ${ }^{23}$

Em $O$ amanuense as recordações sobre as festas juninas aparecem do seguinte modo:

Por que, afinal, essa fogueira, esse balão que se queima no ar e os foguetes, que vão atrás dos balōes, hão de fazer-me inclinar sobre mim mesmo, para viajar pelo tempo afora, perdidamente, em busca de um balão que as monçōes carregaram para outras latitudes $?^{24}$

Aires esvazia a importância da lembrança das festas. Para ele, a única função de evocar aqueles momentos é simplesmente lembrar-se deles - e, quando muito, notar com certa melancolia a diferença entre o passado e o presente. $O$ passado tende a congelar-se em si próprio e conviver com o presente apenas enquanto lembrança A não valendo a pena nem mesmo tentar recuperar algo daquele tempo, que está irremediavelmente perdido.

23 MACHADO DE ASSIS, op. cit., p. 68.

24 ANJOS, Cyro dos. op. cit., p. 39. 
Belmiro, por sua vez, faz uma tentativa de recuperar certos valores perdidos no tempo. Em princípio, como o personagem-narrador de Proust, o amanuense busca, com a evocação do passado, recuperar algo, sensações que a memória pode tornar presente. No instante seguinte, porém, ele desiste dessa busca, questionando se existe uma razão para fazê-la. Ao contrário do que acontece com Aires, lembrar para Belmiro pode projetar algum elemento do passado no presente, ou, pelo menos, atualizar certas sensações que tiveram vez no passado, contrapondo-o como uma espécie de força positiva ao presente que se revela pouco atrativo - os tempos eram outros, melhores, mas podem voltar através da memória. No entanto, dura pouco essa expectativa de Belmiro, dando vez à dúvida da utilidade e mesmo da possibilidade dessa recuperação do tempo: "Vã tentativa de reintegração de porções que se desprenderam da alma nesse trajeto imenso. Em cada ramo à beira do caminho ficou um pouco de nossas vestes e é inútil voltar, porque os bichos comeram os trapos que o vento não levou" 25 .

Ao duvidar da possibilidade de recuperação do passado, Belmiro está próximo a Aires, o que reforça os pontos de contato entre os dois romances. $\mathrm{O}$ ceticismo, o cinismo e a ironia - apontados para os outros ou para si próprio acabam sendo traços marcantes nos dois narradores, à medida que são quase o veículo dessa dúvida. Porém, a relação dos personagens-narradores com o passado e com o espaço social que lhes reserva o presente faz com que os dois romances percorram caminhos distintos, provocando o surgimento de outras relações. Se a descrença é o ponto de partida de todas as observações de Aires, é o ponto de chegada das de Belmiro.

O diálogo que se estabelece, então, entre $O$ amanuense Belmiro e Memorial de Aires é realmente mais intenso do que a simples reprodução de fórmulas ou procedimentos estilísticos. O romance de Cyro dos Anjos pode, de fato, promover um redimensionamento do texto de Machado, especialmente no que diz respeito ao protagonista Aires. Ao concentrarmos a análise no componente da memória, podemos especular se Aires não teria passado por um processo semelhante àquele pelo qual Belmiro passa - se Belmiro não é um Aires trinta anos mais jovem.

Assim, Cyro dos Anjos pode ser chamado de machadiano, não por coincidência ou colagem, mas por natureza. 


\section{RESUMO}

Ao estrear no romance Cyro dos Anjos foi identificado pela crítica como um autor machadiano, qualificação que - sempre referida mas pouco estudada - acompanhou-o ao longo de sua carreira de romancista. Este artigo tem o objetivo de aprofundar, através do aspecto da exploração da memória, as relações entre Cyro dos Anjos e Machado de Assis por meio dos romances $O$ Amanuense Belmiro e Memorial de Aires.

\section{ABSTRACT}

Since his first novel was published Cyro dos Anjos was called a Machadiano author. This definition was always referred to, although little studied. This essay intends to turn the Machadiano definition into something more solid, by analysing memorialistic aspects in both Cyro dos Anjos And Machado de Assis's novels $O$ Amanuense Belmiro and Memorial de Aires.

\section{REFERÊNCIAS BIBLIOGRÁFICAS}

ANDRADE, Carlos Drummond de. O Amanuense, o Trovador e o Cigano. Folha da Manhä, 31 jul. 1949, São Paulo.

ANDRADE, Mário de. Vida literária. São Paulo: Edusp/Hucitec, 1993.

ANJOS, Cyro dos. $O$ amanuense Belmiro. Rio de Janeiro: José Olympio, 1980.

ASSIS, Machado de. Menorial de Aires. São Paulo: Cultrix, 1961.

BOSI, Alfredo. Uma Figura Machadiana. In: . Céu, Inferno, São Paulo, Ática, 1988.

BOSI, Ecléa. Memória e sociedade: Lembranças de velhos. São Paulo: T. A. Queiroz/Edusp, 1987.

CANDIDO, Antonio. Prefácio Inútil. In: ANDRADE, Oswald, Um Homem sem profissão: sob as ordens de mamãe. Rio de Janeiro: José Olympio, 1954.

Estratégia. In: . Brigada ligeira. São Paulo: Martins, s/d.

FRIEIRO, Eduardo. O Amanuense Belmiro, Romance de Cyro dos Anjos. In: Páginas de crítica e outros escritos. Belo Horizonte. Itatiaia, 1955.

MENESES, Ulpiano Bezerra de. Identidade Cultural e Arqueologia. In: BOSI, Alfredo (org.). Cultura brasileira. São Paulo: Ática, 1988.

MORETZOHN, Virgílio. Amores e Dores de um Estrategista da Literatura. O Globo, 21 nov. 1981, Rio de Janeiro. 
PEREIRA, Lúcia Miguel. Machado de Assis. São Paulo: Companhia Editora Nacional, 1946.

REGO, José Lins do. Gordos e magros. Rio de Janeiro: Casa do Estudante do Brasil, 1942.

SCHWARZ, Roberto. Ao vencedor as batatas, São Paulo, Duas Cidades, 1981. Sobre "O amanuense Belmiro". In: O pai de família e outros estudos, Rio de Janeiro: Paz e Terra, 1979.

SIMÕES, João Gaspar. O Amanuense Belmiro. In:__. Critica I: A prosa e o romance contemporâneos. Porto: Livraria Latina Editora, 1942. 